\title{
Evaluation of Iron-Based Metal-Organic Framework Activation Temperature in Acetylene Adsorption
}

Gregory S. Day, ${ }^{1 *}$ Gerard T. Rowe, ${ }^{2}$ Carlos Ybanez, ${ }^{1}$ Ray O. Ozdemir, ${ }^{1}$ Jason Ornstein ${ }^{1}$

${ }^{1}$ framergy, Inc., 800 Raymond Stotzer Pkwy 2011, College Station, TX 77845

2Department of Chemistry and Physics, University of South Carolina Aiken, University Parkway, Aiken, South Carolina 29801

E-mail: greg@framergy.com

\section{Abstract}

One of the major issues regarding long-term human space exploration is the need for a breathable atmosphere. Typically, this requires both removal of exhaled $\mathrm{CO}_{2}$ and generation or recovery of oxygen. NASA's current technology only operates at about $50 \%$ efficiency due to the need to vent methane that is produced during the $\mathrm{CO} 2$ reduction process. One method of improving the efficiency of this process is through plasma pyrolysis, wherein the methane is pyrolyzed to produce hydrogen and various dehydrogenated carbon byproducts, with acetylene being one of the main components of this byproduct stream. Unfortunately, while the concentration of this effluent is generally high in hydrogen (>90\% typically) the presence of this acetylene can act as a poison for the Sabatier catalysts, requiring a removal step. Metal-organic frameworks (MOFs) represent a valuable method removing these unsaturated hydrocarbons due to their high tunability, particularly through the incorporation of open metal sites. In this study, two common iron-based MOFs, MIL-100 and PCN-250, were studied for their ability to adsorb acetylene. A combination of gas adsorption and density functional theory results show the ability of these materials to undergo a thermal induced reduction event results in an improvement in gas adsorption performance, which appears to be at least partially due to the increased presence of $\pi$-backbonding towards the acetylene molecules.

\section{Introduction}


The future of space exploration lies with longer term missions to the moon, Mars, and beyond. However, there are many current factors that limit the potential mission duration, not the least of which is the need to resupply oxygen to the astronauts. Currently, the International Space Station (ISS) has a number of processes that are utilized to recycle the air and produce oxygen, namely the Air Revitalization System (ARS), which combines a number of various subsystems, in particular the Oxygen Generating Assembly (OGA), and the Sabatier System. ${ }^{1-2}$

The OGA operates via an electrolysis to separate water into oxygen and hydrogen. ${ }^{3}$ This hydrogen is then utilized to the $\mathrm{CO}_{2}$ in the carbon dioxide reduction assembly (CRA) through the Sabatier reaction, wherein $\mathrm{CO}_{2}$ is reacted with $\mathrm{H}_{2}$ over a ruthenium-alumina catalyst, ${ }^{4}$ producing methane and water. ${ }^{5-7}$ The methane produced via this process is typically vented, ${ }^{8}$ which unfortuantely, results in a loss of about half of the hydrogen atoms utilized in the Sabatier reaction ${ }^{4}$ and thus limiting the total oxygen recovery. One potential method that is being studied to improve the overall oxygen recovery is through the use of the plasma pyrolysis assembly (PPA) to convert methane to acetylene and hydrogen, recovery about $75 \%$ of the hydrogen from the methane. ${ }^{4}$ This process works via the production of microwave induced plasma that produces hydrogen as well as a variety of reduced carbon products, including aromatics and most notably, acetylene. ${ }^{9}$

Unfortunately, acetylene is a known poison for Sabatier type catalysts due to the strong interaction and reactivity of acetylene towards the catalysts. ${ }^{10}$ Because of that, there has been a strong interest in finding methods of removing acetylene from the hydrogen streams. ${ }^{11}$ In particular, due to the limitations of space exploration, any system that would separate out the acetylene should have minimal equipment requirements or energy inputs. ${ }^{11}$ This requires a process that can operate at or near room temperature and at the relatively low pressure of the PPA effluent (50-100 torr). ${ }^{11}$

These process limitations result in a limited number of options for the efficient separation of acetylene from hydrogen. One of the main systems of interest is the use of sorbent based approaches. ${ }^{11}$ Amongst 
all classes of sorbents, metal-organic frameworks (MOFs), materials produced from the combination of organic linkers and metal oxo clusters, are quickly becoming of great interest for this process. ${ }^{12-14}$ This is because of the structural features of MOFs, such as their high surface areas, ${ }^{15-16}$ and the presence of open metal sites. ${ }^{17-18}$

Open metal sites, also known as coordinatively unsaturated sites, are an important factor in the use of MOFs for acetylene adsorption and separation. Acetylene, due to containing unsaturated $\pi$ centers, can readily interact with certain metals through $\pi$-backdonation, a process that is well studied in organometallic chemistry ${ }^{19}$ and has been utilized in traditional sorbents such as zeolites ${ }^{20}$ or porous silicas. ${ }^{21}$ Backdonation works through donation of electron density from a metal center into the $\pi^{*}$ orbitals of an alkene or alkyne. This mechanism provides an extra boost in binding affinity relative to $\sigma$ donation, where the electrons in the double or triple bond are donated to the metal center. ${ }^{19,22}$ Backdonation requires electrons in the valence orbitals of the metal center in order to function, which limits the MOFs that can be utilized to species from either the middle transition metals $(\mathrm{Cr}, \mathrm{Mn}, \mathrm{Fe})^{23}$ or late transition metals $(\mathrm{Ni}, \mathrm{Cu})^{24}$ in low oxidation states, in addition to requiring MOFs that have readily pore accessible open metal sites.

Amongst the MOF clusters that have been studied for their open metal site formation, one species of interest is the trinuclear iron oxo $\left(\mathrm{Fe}_{3} \mathrm{O}\right)$ cluster. Two of the most well-known MOFs with the $\mathrm{Fe}_{3} \mathrm{O}$ cluster are MIL-100 ${ }^{25}$ and $\mathrm{PCN}-250^{26}$ (also known as MIL-127). ${ }^{27}$ Due to the redox accessibility of iron the $\mathrm{Fe}_{3} \mathrm{O}$ cluster has been noted to undergo reduction events in both MOFs, ${ }^{23,}{ }^{28-30}$ producing a mixed valent $\mathrm{Fe}(\mathrm{III})_{2} \mathrm{Fe}(\mathrm{II}) \mathrm{O}$ cluster under high temperature $\left(\sim 220^{\circ} \mathrm{C}\right)$ thermal treatment. This mixed valent state is particularly important for the adsorption of certain unsaturated molecules, such as alkenes and alkynes, as the Fe(II) sites have improved $\pi$-backdonation capabilities compared to the Fe(III) centers. ${ }^{28,31}$ This improved backdonation allows for a higher adsorption enthalpy at these open metal sites, thus leading to an improvement in adsorption capacity, particularly at the low adsorption pressures. ${ }^{32}$ For this project the 
two MOFs, MIL-100 and PCN-250 were analyzed for their gas adsorption performance towards the byproducts of methane pyrolysis, with an evaluation of activation temperature showed a remarkable improvement in gas uptake, due to the production of the mixed valent states within the MOFs.

\section{Results and Discussion}

Both MOFs evaluated are currently being commercialized by framergy under the AYRSORB ${ }^{\mathrm{TM}}$ label, with MIL-100 known as AYRSORB ${ }^{\mathrm{TM}}$ F100 and PCN-250 known as AYRSORB ${ }^{\mathrm{TM}}$ F250. For these tests, the MOF samples were supplied from commercial batches of the two MOFs, PXRD analysis (Figure S1) shows that the material structures match that of the known material.

Initial characterization of these materials thermal properties was conducted via thermogravimetric-mass spectrometry (TGA-MS). Previous reports have shown that PCN-250 undergoes a noticeable mass loss in the $\sim 220{ }^{\circ} \mathrm{C}$ temperature region, corresponding to the partial decarboxylation of the ligand..$^{29}$ The data collected here confirms that analysis, with $\mathrm{PCN}-250$ exhibiting a small increase in a $\mathrm{CO}_{2}$ signal corresponding to this decarboxylation event (Figure S2). Meanwhile, there is no noticeable $\mathrm{CO}_{2}$ release event observed in that region in MIL-100 (Figure S3). No mention of decarboxylation has ever been made in regards to the MIL-100 redox event, suggesting that the process does not proceed via a ligand effected redox event. ${ }^{23}$ Indeed, the only product gas that is observed in that region is a slight uptick in the water signal, suggesting that the redox event in MIL-100 is potentially related to a loss of the terminal hydroxide ligand.

Initial adsorption isotherms of the two MOFs were collected utilizing two different activation temperatures, $150^{\circ} \mathrm{C}$ and $250{ }^{\circ} \mathrm{C} .150^{\circ} \mathrm{C}$ activation was chosen as it can readily result in removal of guest molecules in the pores but does not result in any redox events in either PCN-250 or MIL-100. Meanwhile, $250{ }^{\circ} \mathrm{C}$ was chosen for the higher temperature activation due to this being above the thermal redox activation temperatures for both MOFs, ensuring complete formation of the mixed valent state in both cases. Porosity analysis of the four resulting materials was conducted via $\mathrm{N}_{2}$ adsorption analysis. For MIL- 
100, there was minimal change in the Brunauer-Emmett-Teller ${ }^{33}$ (BET) surface area, only increasing by about $70 \mathrm{~m}^{2} / \mathrm{g}$ upon activation (Table S1). Meanwhile, PCN-250 shows a significant increase in surface area, going up from 1333 to $1640 \mathrm{~m}^{2} / \mathrm{g}$, an increase of $307 \mathrm{~m}^{2} / \mathrm{g}$. This drastic change is likely due to the smaller pores of PCN-250, with complete removal of guest molecules being slightly hindered at $150{ }^{\circ} \mathrm{C}$. In order to be utilized for hydrogen cleanup from the PPA effluent stream, each of these materials should show minimal adsorption for hydrogen. Hydrogen molecules are also capable of undergoing backdonation based adsorption, with these processes having been attempted in the past to increase hydrogen storage capacities. ${ }^{34}$ Even after activation at $250^{\circ} \mathrm{C}$, neither MOF exhibits a room temperature adsorption capacity for hydrogen greater than $0.06 \mathrm{mmol} \mathrm{H}_{2} / \mathrm{g}$ of $\mathrm{MOF}$, indicating minimal hydrogen adsorption under PPA effluent conditions (Figure S3).
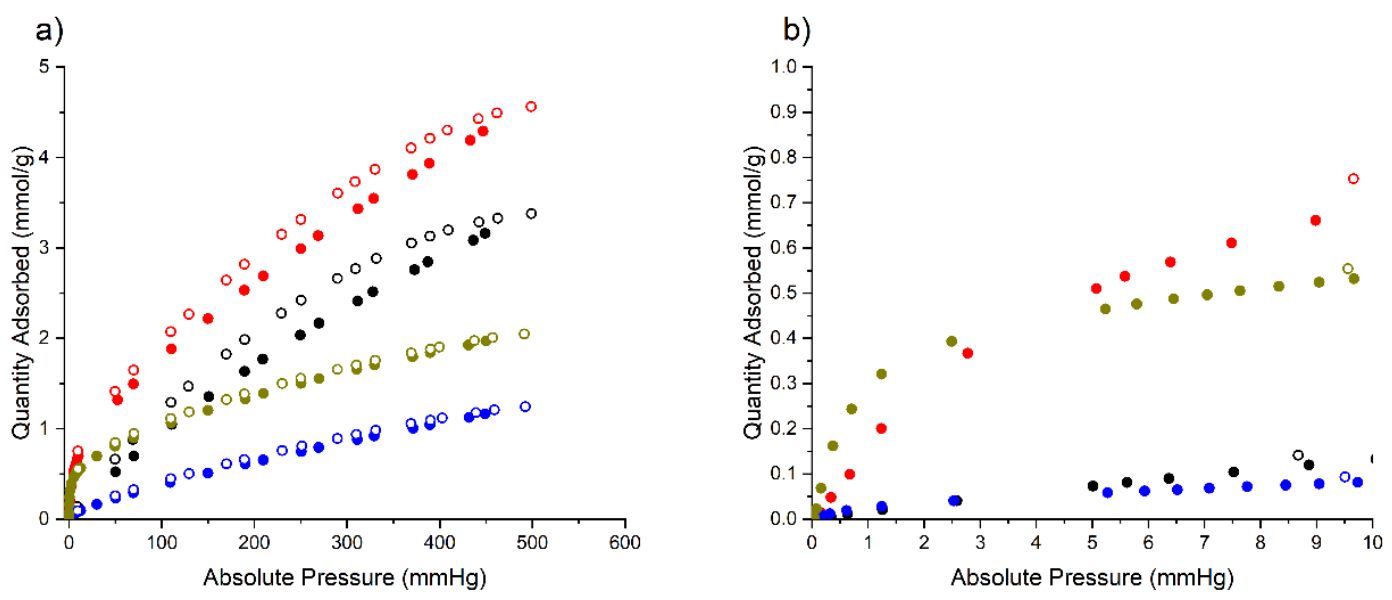

- / $0 \mathrm{PCN}-250150^{\circ} \mathrm{C}$ Activated - / O $\mathrm{PCN}-250250^{\circ} \mathrm{C}$ Activated

- I $\circ \mathrm{MIL}-100150^{\circ} \mathrm{C}$ Activated $\bullet / \circ \mathrm{MIL}-100250^{\circ} \mathrm{C}$ Activated

Figure 1. a) $295 \mathrm{~K}$ acetylene adsorption isotherms for MIL-100 and PCN-250 activated at $150 \mathrm{C}$ and $250 \mathrm{C}$, the microporous PCN-250 shows a better overall performance compared to MIL-100, b) closeup view of the low pressure region of the data, showing that performance under working conditions are more heavily influenced by activation temperature. 
Acetylene adsorption experiments were conducted up to $500 \mathrm{mmHg}$ to gain a better understanding of the effect of activation temperature on the adsorption of unsaturated species. Initial observation showed that the microporous PCN-250 generally had higher uptake than the mesoporous MIL-100, with PCN-250 showing an uptake at $500 \mathrm{mmHg}$ of over $4.5 \mathrm{mmol} / \mathrm{g}$, while MIL-100 only reaches about $2.0 \mathrm{mmol} / \mathrm{g}$ (Figure 1). However, the PPA effluent pressure is typically quite low $(90-110 \mathrm{mmHg})$, and acetylene only takes up a small fraction of that gas stream $(6-8 \%),{ }^{35}$ thus a better understanding of the performance of these MOFs requires evaluation of their low pressure performance. Adsorption in the $0-10 \mathrm{mmHg}$ range shows instead that the performance is primarily dominated by the activation temperature, with both the MIL-100 and PCN-250 samples activated at $250{ }^{\circ} \mathrm{C}$ showing a noticeable increase in uptake compared to the $150 \mathrm{C}$ activated samples (Figure $\mathbf{1 b}$ ). This suggests that the main driver of the adsorption at low pressures is the availability and bonding strength of the open metal sites within the iron MOFs.

Similar analysis was conducted on the other components of the PPA effluent stream, mainly carbon monoxide (Figure S4), carbon dioxide (Figure S5), ethylene (Figure S6), and ethane (Figure S7). Based upon information provided by NASA, the PPA effluent stream (total pressure $90-110 \mathrm{mmHg}$ ) should only have small amounts of each of these gases, 0-3.23 mol\% carbon monoxide (0-3.6 mmHg), 0-0.08 mol\% carbon dioxide (0-0.09 $\mathrm{mmHg}), 0.08-0.10 \mathrm{~mol} \%$ ethylene $(0.07-0.11 \mathrm{mmHg})$, and $0.01 \mathrm{~mol} \%$ ethane $(0.01$ $\mathrm{mmHg}){ }^{35}$ The PPA effluent pressure analysis typically shows that $250{ }^{\circ} \mathrm{C}$ activation shows an improved adsorption for each gas, with only ethane adsorption showing a significantly stronger preference for MOF identity (PCN-250 versus MIL-100) compared to activation temperature. Meanwhile, ethylene is the only gas that shows a greater adsorption performance at high pressure in the $150{ }^{\circ} \mathrm{C}$ activated PCN-250 compared to the $250^{\circ} \mathrm{C}$ activated samples. Previous studies in ethylene and ethane adsorption in PCN250 have shown that adsorption does not primarily occur at the open metal sites, but is instead mainly dependent on Van der Waals interactions with the aromatic rings and azo bond of the ligand. ${ }^{36}$ It has also been noted that hydrogen bonding type interactions can be observed in ethane selective adsorption in 
MOFs. ${ }^{37}$ The $150{ }^{\circ} \mathrm{C}$ activated samples should still have water or hydroxide ions sitting on the open metal sites, potentially explaining the higher adsorption. Carbon monoxide shows a much stronger affinity towards $250{ }^{\circ} \mathrm{C}$ activated MIL-100 at high pressures compared to $150{ }^{\circ} \mathrm{C} \mathrm{PCN}-250$, likely due to the significantly stronger influence $\pi$-backdonation has on CO-metal interactions compared to the other gases. ${ }^{38-40}$

The data from the adsorption isotherms was subsequently fitted via the Langmuir equation for subsequent analysis of the gas selectivity. ${ }^{41-42}$ Each gas was analyzed for their selectivity over hydrogen at a constant ratio described by the average of the PPA effluent pressures (hydrogen: $90.03 \%$, Acetylene: $7.13 \%$, ethylene: $0.09 \%$, ethane: $0.01 \%$, carbon monoxide: $1.62 \%$, and carbon dioxide $0.04 \%)$. The adsorbed gas amounts were calculated for each of these gases at the designated percentage of the total pressure. Binary selectivities were calculated via the IAST method ${ }^{43}$ over a range of total pressures. This method of analysis was chosen as the product ratio in the PPA effluent is not expected to differ to a great degree, but one possible method of altering the separation could be through increasing or lowering the total pressure of the system. Both MOFs under both activation conditions show selectivities greater than 1 for all gases up to $1000 \mathrm{mmHg}$ (Figures 2, S8-11).
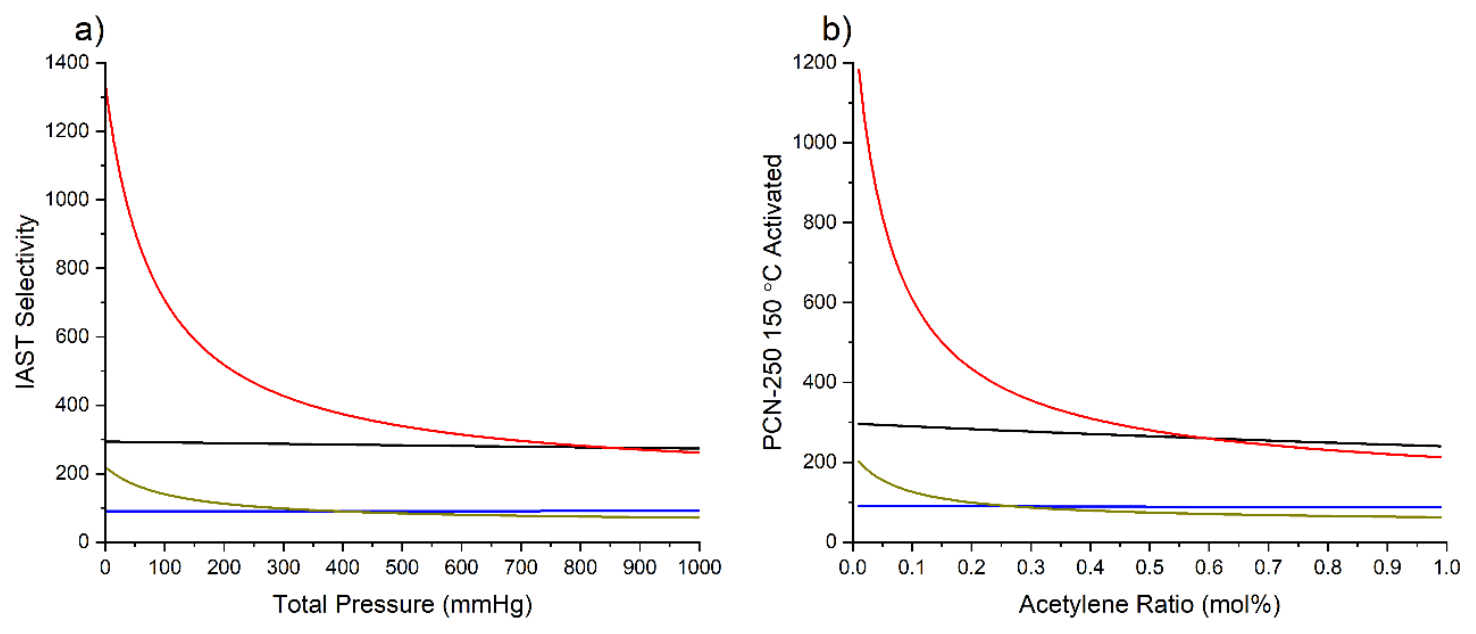

$\longrightarrow \mathrm{PCN}-250150^{\circ} \mathrm{C}$ Activated $\longrightarrow \mathrm{PCN}-250250^{\circ} \mathrm{C}$ Activated $\longrightarrow$ MIL-100 $150^{\circ} \mathrm{C}$ Activated $\longrightarrow$ MIL-100 $250{ }^{\circ} \mathrm{C}$ Activated 
Figure 2. Selectivity of acetylene over hydrogen for the four MOF systems a) over a $1000 \mathrm{mmHg}$ pressure range, b) by varying the concentration of acetylene in a binary acetylene hydrogen ratio.

The $150{ }^{\circ} \mathrm{C}$ activated samples show relatively flat selectivities over the pressure range, with only slight changes over the pressure range analyzed. Meanwhile, both the $250 \mathrm{C}$ activated samples showed a sharp increase in selectivity for both acetylene and ethylene at low pressures. This is likely due to the strong effects of adsorption on the open metal sites. This adsorption primarily occurs at low pressure, as these sites are the first to be filled, as such, this highly improved selectivity drops off dramatically with an increasing pressure. Analysis of the selectivity of acetylene over hydrogen was also conducted by altering the gas ratio at a constant pressure of $100 \mathrm{mmHg}$. This data shows a similar selectivity trend as the pressure sweep analysis (Figure 2b). The drop in selectivity with an increase in acetylene concentration is likely due to the higher concentration of gas more readily saturating the open metal sites, so a majority of the adsorbed gas is simply adsorbed onto the less selective surfaces of the MOF ligands, resulting in a lowered selectivity compared to hydrogen.

The selectivity data shows a strong preference of the unsaturated acetylene and ethylene towards the highly activated $\left(250^{\circ} \mathrm{C}\right)$ samples. Further analysis of this preference was conducted via heat of adsorption measurements for acetylene adsorption in the MOF systems. Heat of adsorption measurements were calculated via the Clausius-Clapeyron equation, ${ }^{44-45}$ which provides the isosteric heat of adsorption as a function of gas loading. ${ }^{46-47}$ The analysis was based upon the collection of single component adsorption isotherms of acetylene at three different temperatures, $0{ }^{\circ} \mathrm{C}, 2{ }^{\circ} \mathrm{C}$, and $34^{\circ} \mathrm{C}$ (Figures S12-15). In general, the performance of the four MOF systems matches what was observed previously, PCN-250 shows an increase in adsorption compared to MIL-100. As expected, the amount of adsorbed gas is inversely related to the temperature of adsorption, with $0{ }^{\circ} \mathrm{C}$ showing the highest adsorption quantities at all pressures. 
There is a notable difference in the heat of adsorption values as a function of activation temperature, with the $150{ }^{\circ} \mathrm{C}$ activated samples showing a relatively flat heat of adsorption as a function of coverage (Figure 3). There is a small boost in heat of adsorption at low coverage, $21.6 \mathrm{~kJ} / \mathrm{mol}$ for MIL-100 and $26.0 \mathrm{~kJ} / \mathrm{mol}$ for PCN-250, but as the coverage increases the heat of adsorption quickly drops down to $17-19 \mathrm{~kJ} / \mathrm{mol}$ for MIL-100 and 22-23 kJ/mol for PCN-250. This drop in heat of adsorption is likely related to the saturation of open metal sites in the $150{ }^{\circ} \mathrm{C}$ activated samples, as the $150{ }^{\circ} \mathrm{C}$ activated samples have a lower availability of open metal sites compared to the $250{ }^{\circ} \mathrm{C}$ activated samples, it would make sense that they would get saturated at lower coverage.

In addition to showing higher heats of adsorption for greater coverage amounts, the $250{ }^{\circ} \mathrm{C}$ activated samples also show a significant improvement in low coverage heat of adsorption, with MIL-100 starting out at $45.7 \mathrm{~kJ} / \mathrm{mol}$ at $0.01 \mathrm{mmol} / \mathrm{g}$ coverage before dropping slightly to $41.1 \mathrm{~kJ} / \mathrm{mol}$, and PCN-250 showing an initial coverage of $52.9 \mathrm{~kJ} / \mathrm{mol}$ at $0.09 \mathrm{mmol} / \mathrm{g}$ before dropping slightly to $51.5 \mathrm{~kJ} / \mathrm{mol}$. At higher loadings, MOFs show heats of adsorption that begin to converge with that of the $150^{\circ} \mathrm{C}$ activated samples, although MIL-100 does not fully converge in the coverage range covered by this analysis. Convergence of the two graphs would be expected, as the higher loadings should mainly be focused on physisorption of acetylene on the organic linkers of the MOF, with only the low coverage being dependent on the availability and strength of the open metal sites. The increase in baseline heat of adsorption for PCN-250 is expected based upon its microporous structure, which should provide a greater degree of van der Waals interactions towards individual acetylene molecules. 

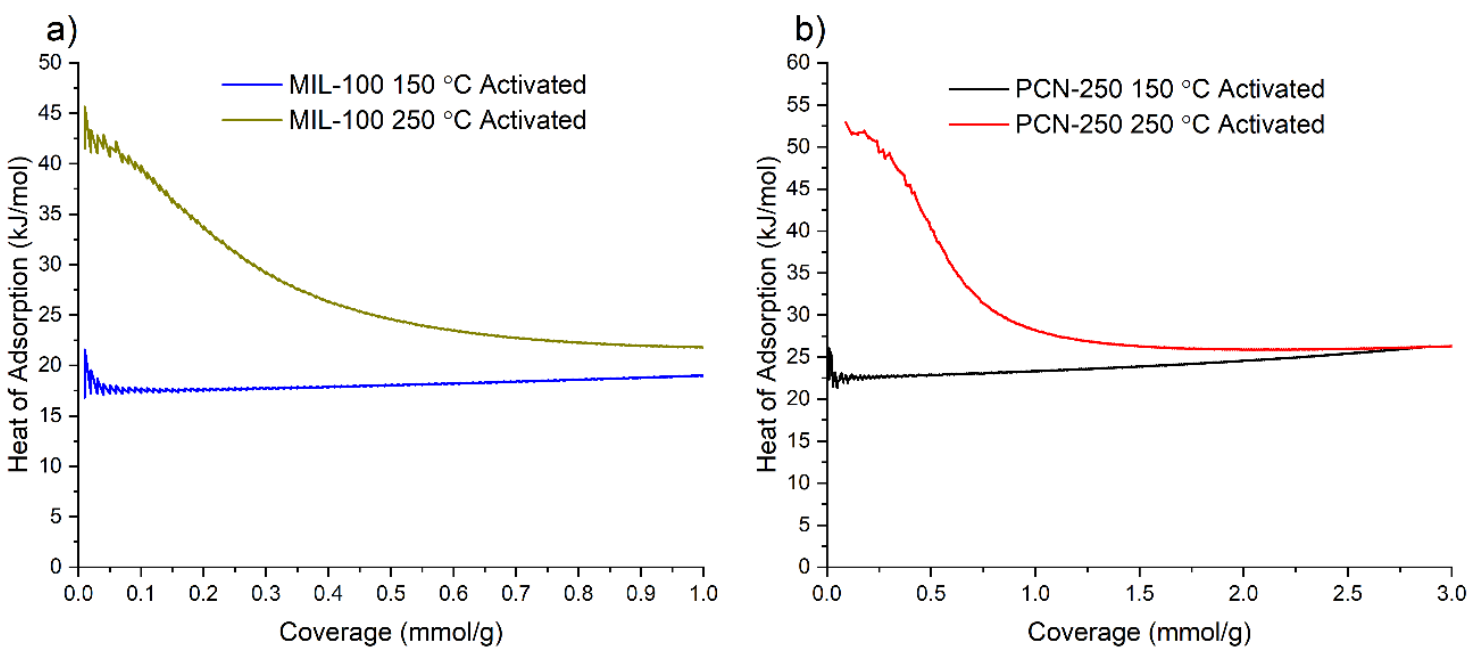

Figure 3. Absolute values of the heat of adsorption as a function of adsorbed acetylene for a) MIL-100 and b) PCN-250. The activation temperature has a strong influence on the adsorption enthalpy at low quantities adsorbed, as the adsorbed acetylene increases the heat of adsorption for the $250{ }^{\circ} \mathrm{C}$ converges to that the $150^{\circ} \mathrm{C}$ Activated samples.

For comparison, a sample of PCN-250-Al, which has not been observed to undergo a reductive decarboxylation mechanism, ${ }^{30}$ was also subjected to $250{ }^{\circ} \mathrm{C}$ activation and acetylene heat of adsorption calculations. The non-reducible Al centers result in a heat of adsorption after $250{ }^{\circ} \mathrm{C}$ activation that is nearly identifical to that of the $150{ }^{\circ} \mathrm{C}$ activated PCN-250-Fe (Figure S17). This result suggests that the activation at $250{ }^{\circ} \mathrm{C}$, with its concurrent reduction event, is important to achieve high acetylene heat of adsorption. In addition, the value for the heat of adsorption at low coverage for the $250{ }^{\circ} \mathrm{C}$ activated samples appears to strongly indicate a weakly chemisorptive material, particularly for PCN-250 which shows an initial heat of adsorption of over $50 \mathrm{~kJ} / \mathrm{mol}$.

To follow up on this hypothesis, density functional theory (DFT) analysis was performed on the PCN-250Fe structure. After collecting an initial optimized geometry of the Fe (III) structure calculations were performed in the presence of acetylene on the Fe sites to gain an understanding of the differences in binding potential between the Fe (III) structure and the mixed valent structure (Figure 4). In addition, 
analysis was also conducted on the PCN-250-Al structure. These results showed an acetylene binding enthalpy of $37.6 \mathrm{~kJ} / \mathrm{mol}, 41.0 \mathrm{~kJ} / \mathrm{mol}$, and $44.4 \mathrm{~kJ} / \mathrm{mol}$ for PCN-250-Al, PCN-250-Fe(III), and PCN-250Fe(II/III) respectively. This represents simply the interaction of acetylene with the cluster and does not account for the differences due to physisorption. Regardless, these results due show a noticeable impact of the metal identity on the binding enthalpy and are also exemplified by a decrease in Fe-C bond lengths going from 2.8182 and $2.8112 \AA$ in the Fe(III) system to 2.7200 and $2.7149 \AA$ in Fe(II/III), which is indicative of noticeably stronger Fe-C binding strengths. Additionally, there was a slight increase in acetylene carbon-carbon bond length observed, going from $1.1974 \AA \AA$ in the free acetylene, to $1.1999,1.2008$, and 1.2014 A in the PCN-250-Al, PCN-250-Fe(III), and PCN-250-Fe(II/III) structures respectively. $\pi$-backdonation works through donation of electron density from the metal center through one of its $d$ orbitals to the $\pi^{*}$ orbitals of the acetylene. As such, evaluation of the degree of backdonation can also be observed through evaluation of the molecular orbitals that involve these two components. In the all Fe (III) system, the acetylene $\pi^{*}$ orbitals are observed in the HOMO -12 MO, with the MO map showing little overlap between the $\pi^{*}$ and the d orbital of one of the iron centers (Figure 4). Meanwhile, the reduced form, also located at HOMO -12 , shows a noticeably larger contribution from the $\pi^{*}$ orbital. The overlap is still low, showing that while there is some improvement in backdonation, the overall level is significantly lower than what is seen in traditional $\pi$-acceptor organometallic complexes. In addition, analysis of the antibonding orbitals associated with the $\sigma$ bond of the acetylene to metal centers, HOMO-9 and HOMO6 in the $\mathrm{Fe}(\mathrm{III})$ and $\mathrm{Fe}(\mathrm{II} / \mathrm{III})$ system respectively, does show a higher contribution from the acetylene in the Fe(II/III) system compared to the Fe(III) system (Table S7). This conclusion is further supported by NBO analysis, which indicates $33 \%$ greater electron density in the acetylene $\pi^{*}$ orbital for the Fe(II/III) system as compared to the Fe(III) system (Table S8). For comparison, NBO analysis of the PCN-250-Al structures shows minimal electron density in the acetylene $\pi^{*}$ orbital, being about $6 \%$ less than the $\mathrm{Fe}(\mathrm{III})$ system, with the PCN-250-Al-acetylene interaction mainly being electrostatic in nature (Figure S19). 

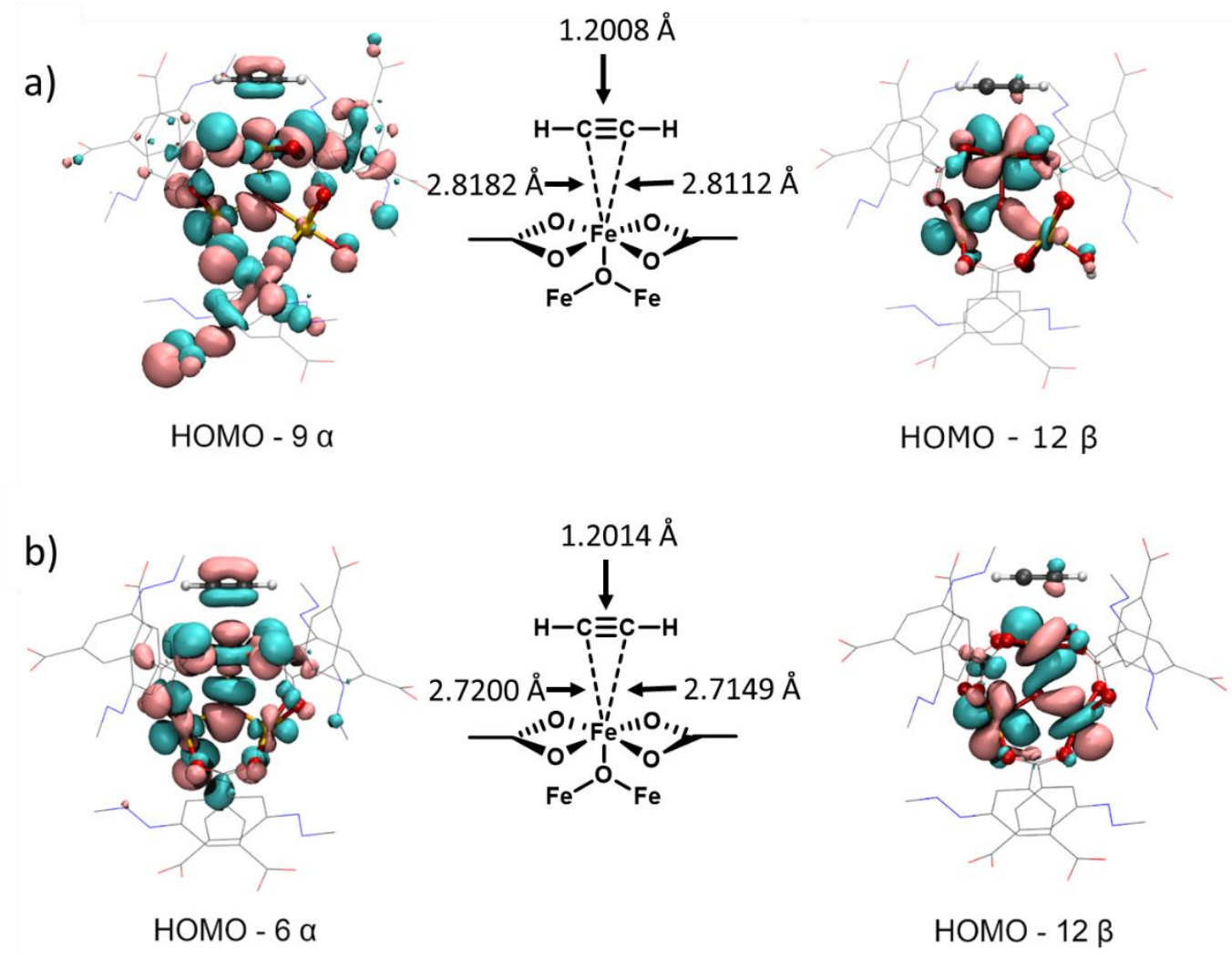

Figure 4. Acetylene-Cluster based orbitals for a) the Fe(III) structure and b) the Fe(II/III) structure. A small amount of $\pi$-backdonation is observed in the HOMO-12 of both structures, with a greater degree observed in the Fe(II/III) structure. There is a significant sigma bonding component as observed in both structures.

\section{Shaped MOF Scale Up}

One of the major limitations of MOF utilization is their formation as fine powders. As such there has been a growing interest in the shaping of MOFs into larger structures that are easier to handle. As part of this work, framergy has worked with a third-party vendor, FEECO International, to produce hundred gram scale batches of spherical granules of both MIL-100 and PCN-250 (Figures S20-21). These granules were produced via spherical granularization using a batch mode pin mixer and disc pelletizer at FEECO's Innovation Center in Green Bay, Wisconsin. The granules were produced utilizing two different binder systems, colloidal silica, and polyvinylbutyral (PVB), both of which were kept as $5 \%$ by weight in the final 
pellets with colloidal silica being diluted in water to wet the MOF and PVB being dissolved in ethanol. Evaluation of these materials was conducted via $22{ }^{\circ} \mathrm{C}$ acetylene adsorption and $77 \mathrm{~K} \mathrm{~N} \mathrm{~N}_{2}$ adsorption analysis. The BET surface areas of all samples were reduced upon granulation, with PCN-250 showing a larger drop for the colloidal silica samples and MIL-100 showing a larger drop for the PVB samples, although the drop in surface area is less significant for MIL-100 than for PCN-250 (Table 1, Figures S2223). The significant drop in surface area for PCN-250 with colloidal silica is likely due to the presence of water in the binder formulation, mostly likely getting trapped in the small pores of PCN-250 more readily than MIL-100. The Acetylene adsorption of PCN-250 with PVB shows only a minimal drop, and the low pressure region strongly matches that of the parent powder (Figures S24-25). Meanwhile, the PCN-250 colloidal silica and the MIL-100 samples show a more significant drop at low pressures, seeing a roughly $40 \%$ drop at $10 \mathrm{mmHg}$. In order to alleviate this, a higher activation condition was performed for the MIL100 colloidal silica sample, with activation at $275{ }^{\circ} \mathrm{C}$ over 3 days showing a recovery of the powdered performance. This suggests that the loss is surface area and gas uptake is primarily driven by incomplete activation of the samples after binding, likely due to worse diffusion kinetics for water in the bound system.

\section{Conclusions}

MOFs have been heavily studied for various gas adsorption and separation applications, however, to offset the major cost component of MOF utilization there is a need to test out these materials in specialized systems with demanding process constraints. The removal of acetylene and other byproducts from NASA's PPA system is one such process, as there is a strong need for a material and system that can be readily operated with low energy inputs. The use of iron-based MOFs, with their mix of physisorption and some weak chemisorption, is one potential avenue to achieve a low cost and low mass purification system. The results herein show that iron-based MOFs can be tuned for their adsorption of acetylene solely through activation temperature conditions, with significantly higher uptakes observed for highly 
activated centers due to the formation of mixed valent open metal sites. This results in a significantly higher heat of adsorption for acetylene compared to the as synthesized MOF, with the binding energy approaching that of traditional chemisorptive systems while still being low enough to allow high vacuum sorbent recovery. DFT analysis suggests that the major component of the adsorption enthalpy is due to $\sigma$ bonding between the acetylene $\pi$ bond and the $d_{z 2}$ orbital of the iron centers. While the amount of $\pi$ backdonation in the structure is minimal, likely due to the high spin nature of the structure, there was a noticeable increase in $d-\pi^{*}$ interaction in the reduced $\mathrm{Fe}(\mathrm{II} / \mathrm{III})$ structure. The thermal reduction process was demonstrated in two distinct iron MOFs, PCN-250 and MIL-100, which both contain the same trinuclear iron oxo cluster, showing that this thermal activation process is dependent on the cluster identity and not the pore geometry. In addition, these two MOFs were produced in granule form at the hundred-gram scale, a first for these materials, with the results showing that even upon granulation these materials can maintain their gas adsorption performance.

\section{Acknowledgements}

Funding for this research was provided by the National Aeronautics and Space Administration (NASA) under the Request for Quotation (RFQ) 80NSSC20761064Q: Development of Metal-Organic Frameworks as Sorbents for Acetylene in Plasma Pyrolysis Effluent Separation. The team would like to acknowledge Timothy J. Giesy, Caitlin E. Meyer, Cara S. J. Black, Walter F. Schneider, Travis Quillen, Brittany Brown, and Jesus A. Dominguez of NASA for discussions related to the project goals. The X-ray Diffraction Laboratory at Texas A\&M University is acknowledged. The authors would like to acknowledge Michael Eidge, Kaanan Krueger, and Ron Eichhorn of FEECO International for their assistance with the MOF granulation work. The authors would like to Acknowledge Professor Hong-Cai Joe Zhou, Hannah Drake, Hengyu Lin, and Joshua Powell of Texas A\&M University for instrument access and sample submission. The authors would like to acknowledge the high performance computing resources provided by the Research Computing program under the Division of Information Technology at the University of South Carolina. 


\section{Conflict of Interest}

The authors declare a financial interest in framergy Inc., a startup company that is commercializing the MOFs studied in this paper.

\section{References}

1. Seedhouse, E., International Space Station Life Support System. In Life Support Systems for Humans in Space, Seedhouse, E., Ed. Springer International Publishing: Cham, 2020; pp 151-179.

2. Bagdigian, R. M.; Dake, J.; Gentry, G.; Gault, M. In International Space Station Environmental Control and Life Support System Mass and Crewtime Utilization In Comparison to a Long Duration Human Space Exploration Mission, 45th International Conference on Environmental Systems: 2015.

3. Tobias, B.; Garr, J.; Erne, M., International Space Station Water Balance Operations. In 41st International Conference on Environmental Systems, American Institute of Aeronautics and Astronautics: 2011.

4. Wheeler, R.; Hadley, N.; Dahl, R.; Abney, M.; Greenwood, Z.; Miller, L.; Medlen, A. In Advanced Plasma Pyrolysis Assembly (PPA) Reactor and Process Development, 42nd International Conference on Environmental Systems, 2012; p 3553.

5. Vogt, C.; Monai, M.; Kramer, G. J.; Weckhuysen, B. M., The renaissance of the Sabatier reaction and its applications on Earth and in space. Nature Catalysis 2019, 2 (3), 188-197.

6. Samplatsky, D.; Grohs, K.; Edeen, M.; Crusan, J.; Burkey, R., Development and Integration of the Flight Sabatier Assembly on the ISS. In 41st International Conference on Environmental Systems, American Institute of Aeronautics and Astronautics: 2011.

7. Murdoch, K.; Perry, J.; Smith, F. Sabatier engineering development unit; 0148-7191; SAE Technical Paper: 2003.

8. Jones, H. W., Sources and Uses of Methane in Space. In 43rd International Conference on Environmental Systems, American Institute of Aeronautics and Astronautics: 2013. 
9. Atwater, J. E.; Wheeler, R. R.; Hadley, N. M.; Dahl, R. W.; Carrasquillo, R. L., Hydrogen Recovery by Methane Decomposition in a Microwave Plasma Reactor. SAE International Journal of Aerospace 2009, $1(1), 337-346$.

10. Murdoch, K.; Greenwood, Z.; Blanchard, R.; Stracensky, T.; Sharma, M.; Mukerjee, S.; Pavlicek, R.; DeCastro, E. S. In Closed-Loop Hydrogen Recovery Enabled by Electrochemical Hydrogen Separation, 49th International Conference on Environmental Systems: 2019.

11. Abney, M.; Miller, L.; Barton, K., Evaluation of Sorbents for Acetylene Separation in Atmosphere Revitalization Loop Closure. In 41st International Conference on Environmental Systems, American Institute of Aeronautics and Astronautics: 2011.

12. Xiang, S.; Zhou, W.; Gallegos, J. M.; Liu, Y.; Chen, B., Exceptionally High Acetylene Uptake in a Microporous Metal-Organic Framework with Open Metal Sites. Journal of the American Chemical Society 2009, 131 (34), 12415-12419.

13. Xiang, S.; Zhou, W.; Zhang, Z.; Green, M. A.; Liu, Y.; Chen, B., Open Metal Sites within Isostructural Metal-Organic Frameworks for Differential Recognition of Acetylene and Extraordinarily High Acetylene Storage Capacity at Room Temperature. Angewandte Chemie International Edition 2010, 49 (27), 46154618.

14. Day, G. S.; Drake, H. F.; Zhou, H.-C.; Ryder, M. R., Evolution of porous materials from ancient remedies to modern frameworks. Communications Chemistry 2021, 4 (1), 114.

15. Wang, Z.; Ge, L.; Li, M.; Lin, R.; Wang, H.; Zhu, Z., Orientated growth of copper-based MOF for acetylene storage. Chemical Engineering Journal 2019, 357, 320-327.

16. Li, H.; Wang, K.; Sun, Y.; Lollar, C. T.; Li, J.; Zhou, H.-C., Recent advances in gas storage and separation using metal-organic frameworks. Materials Today 2018, 21 (2), 108-121. 
17. Kökçam-Demir, Ü.; Goldman, A.; Esrafili, L.; Gharib, M.; Morsali, A.; Weingart, O.; Janiak, C., Coordinatively unsaturated metal sites (open metal sites) in metal-organic frameworks: design and applications. Chemical Society Reviews 2020, 49 (9), 2751-2798.

18. Kulkarni, A. R.; Sholl, D. S., Screening of Copper Open Metal Site MOFs for Olefin/Paraffin Separations Using DFT-Derived Force Fields. The Journal of Physical Chemistry C 2016, 120 (40), 2304423054.

19. Yu, Y.; Smith, J. M.; Flaschenriem, C. J.; Holland, P. L., Binding Affinity of Alkynes and Alkenes to Low-Coordinate Iron. Inorganic Chemistry 2006, 45 (15), 5742-5751.

20. Aguado, S.; Bergeret, G.; Daniel, C.; Farrusseng, D., Absolute Molecular Sieve Separation of Ethylene/Ethane Mixtures with Silver Zeolite A. Journal of the American Chemical Society 2012, 134 (36), $14635-14637$.

21. Padin, J.; Yang, R. T., Tailoring New Adsorbents Based on $\pi$-Complexation: Cation and Substrate Effects on Selective Acetylene Adsorption. Industrial \& Engineering Chemistry Research 1997, 36 (10), 4224-4230.

22. Dias, H. V. R.; Flores, J. A.; Wu, J.; Kroll, P., Monomeric Copper(I), Silver(I), and Gold(I) Alkyne Complexes and the Coinage Metal Family Group Trends. Journal of the American Chemical Society 2009, $131(31), 11249-11255$.

23. Leclerc, H.; Vimont, A.; Lavalley, J.-C.; Daturi, M.; Wiersum, A. D.; Llwellyn, P. L.; Horcajada, P.; Férey, G.; Serre, C., Infrared study of the influence of reducible iron(iii) metal sites on the adsorption of $\mathrm{CO}, \mathrm{CO} 2$, propane, propene and propyne in the mesoporous metal-organic framework MIL-100. Physical Chemistry Chemical Physics 2011, 13 (24), 11748-11756.

24. Liao, Y.; Zhang, L.; Weston, M. H.; Morris, W.; Hupp, J. T.; Farha, O. K., Tuning ethylene gas adsorption via metal node modulation: Cu-MOF-74 for a high ethylene deliverable capacity. Chemical Communications 2017, 53 (67), 9376-9379. 
25. Horcajada, P.; Surblé, S.; Serre, C.; Hong, D.-Y.; Seo, Y.-K.; Chang, J.-S.; Grenèche, J.-M.; Margiolaki, I.; Férey, G., Synthesis and catalytic properties of MIL-100(Fe), an iron(iii) carboxylate with large pores. Chemical Communications 2007, (27), 2820-2822.

26. Feng, D.; Wang, K.; Wei, Z.; Chen, Y.-P.; Simon, C. M.; Arvapally, R. K.; Martin, R. L.; Bosch, M.; Liu, T.-F.; Fordham, S.; Yuan, D.; Omary, M. A.; Haranczyk, M.; Smit, B.; Zhou, H.-C., Kinetically tuned dimensional augmentation as a versatile synthetic route towards robust metal-organic frameworks. Nature Communications 2014, 5 (1), 5723.

27. Dhakshinamoorthy, A.; Alvaro, M.; Chevreau, H.; Horcajada, P.; Devic, T.; Serre, C.; Garcia, H., Iron(iii) metal-organic frameworks as solid Lewis acids for the isomerization of $\alpha$-pinene oxide. Catalysis Science \& Technology 2012, 2 (2), 324-330.

28. Yoon, J. W.; Seo, Y.-K.; Hwang, Y. K.; Chang, J.-S.; Leclerc, H.; Wuttke, S.; Bazin, P.; Vimont, A.; Daturi, M.; Bloch, E.; Llewellyn, P. L.; Serre, C.; Horcajada, P.; Grenèche, J.-M.; Rodrigues, A. E.; Férey, G., Controlled Reducibility of a Metal-Organic Framework with Coordinatively Unsaturated Sites for Preferential Gas Sorption. Angewandte Chemie International Edition 2010, 49 (34), 5949-5952.

29. Drake, H. F.; Day, G. S.; Vali, S. W.; Xiao, Z.; Banerjee, S.; Li, J.; Joseph, E. A.; Kuszynski, J. E.; Perry, Z. T.; Kirchon, A.; Ozdemir, O. K.; Lindahl, P. A.; Zhou, H.-C., The thermally induced decarboxylation mechanism of a mixed-oxidation state carboxylate-based iron metal-organic framework. Chemical Communications 2019, 55 (85), 12769-12772.

30. Drake, H. F.; Xiao, Z.; Day, G. S.; Vali, S. W.; Chen, W.; Wang, Q.; Huang, Y.; Yan, T.-H.; Kuszynski, J. E.; Lindahl, P. A.; Ryder, M. R.; Zhou, H.-C., Thermal decarboxylation for the generation of hierarchical porosity in isostructural metal-organic frameworks containing open metal sites. Materials Advances 2021, 2 (16), 5487-5493. 
31. Furukawa, S.; Hitomi, Y.; Shishido, T.; Teramura, K.; Tanaka, T., $\pi$ Back-Bonding of Iron(II) Complexes Supported by Tris(pyrid-2-ylmethyl)amine and Its Nitro-Substituted Derivatives. The Journal of Physical Chemistry A 2011, 115 (46), 13589-13595.

32. Lee, K.; Isley, W. C.; Dzubak, A. L.; Verma, P.; Stoneburner, S. J.; Lin, L.-C.; Howe, J. D.; Bloch, E. D.; Reed, D. A.; Hudson, M. R.; Brown, C. M.; Long, J. R.; Neaton, J. B.; Smit, B.; Cramer, C. J.; Truhlar, D. G.; Gagliardi, L., Design of a Metal-Organic Framework with Enhanced Back Bonding for Separation of N2 and CH4. Journal of the American Chemical Society 2014, 136 (2), 698-704.

33. Brunauer, S.; Emmett, P. H.; Teller, E., Adsorption of Gases in Multimolecular Layers. Journal of the American Chemical Society 1938, 60 (2), 309-319.

34. Jaramillo, D. E.; Jiang, H. Z. H.; Evans, H. A.; Chakraborty, R.; Furukawa, H.; Brown, C. M.; HeadGordon, M.; Long, J. R., Ambient-Temperature Hydrogen Storage via Vanadium(II)-Dihydrogen Complexation in a Metal-Organic Framework. Journal of the American Chemical Society 2021, 143 (16), 6248-6256.

35. Abney, M. B.; Greenwood, Z.; Wall, T., Hydrogen Purification and Recycling for an Integrated Oxygen Recovery System Architecture. In 46th International Conference on Environmental Systems, ICES2016-265: Vienna, Austria, 2016.

36. Chen, Y.; Qiao, Z.; Wu, H.; Lv, D.; Shi, R.; Xia, Q.; Zhou, J.; Li, Z., An ethane-trapping MOF PCN-250 for highly selective adsorption of ethane over ethylene. Chemical Engineering Science 2018, 175, 110-117. 37. Liao, P.-Q.; Zhang, W.-X.; Zhang, J.-P.; Chen, X.-M., Efficient purification of ethene by an ethanetrapping metal-organic framework. Nature Communications 2015, 6 (1), 8697.

38. Valenzano, L.; Civalleri, B.; Sillar, K.; Sauer, J., Heats of Adsorption of CO and CO2 in Metal-Organic Frameworks: Quantum Mechanical Study of CPO-27-M (M = Mg, Ni, Zn). The Journal of Physical Chemistry C 2011, 115 (44), 21777-21784. 
39. Martín-Calvo, A.; Lahoz-Martín, F. D.; Calero, S., Understanding Carbon Monoxide Capture Using Metal-Organic Frameworks. The Journal of Physical Chemistry C 2012, 116 (11), 6655-6663.

40. Bloch, E. D.; Hudson, M. R.; Mason, J. A.; Chavan, S.; Crocellà, V.; Howe, J. D.; Lee, K.; Dzubak, A. L.; Queen, W. L.; Zadrozny, J. M.; Geier, S. J.; Lin, L.-C.; Gagliardi, L.; Smit, B.; Neaton, J. B.; Bordiga, S.; Brown, C. M.; Long, J. R., Reversible CO Binding Enables Tunable CO/H2 and CO/N2 Separations in MetalOrganic Frameworks with Exposed Divalent Metal Cations. Journal of the American Chemical Society 2014, $136(30), 10752-10761$.

41. Langmuir, I., THE ADSORPTION OF GASES ON PLANE SURFACES OF GLASS, MICA AND PLATINUM. Journal of the American Chemical Society 1918, 40 (9), 1361-1403.

42. Swenson, H.; Stadie, N. P., Langmuir's Theory of Adsorption: A Centennial Review. Langmuir 2019, 35 (16), 5409-5426.

43. Walton, K. S.; Sholl, D. S., Predicting multicomponent adsorption: 50 years of the ideal adsorbed solution theory. AIChE Journal 2015, 61 (9), 2757-2762.

44. Wisniak, J., Historical development of the vapor pressure equation from dalton to antoine. Journal of Phase Equilibria 2001, 22 (6), 622.

45. Clausius, R., Ueber die bewegende Kraft der Wärme und die Gesetze, welche sich daraus für die Wärmelehre selbst ableiten lassen. Annalen der Physik 1850, 155 (4), 500-524.

46. Mason, J. A.; Sumida, K.; Herm, Z. R.; Krishna, R.; Long, J. R., Evaluating metal-organic frameworks for post-combustion carbon dioxide capture via temperature swing adsorption. Energy \& Environmental Science 2011, 4 (8), 3030-3040.

47. Li, H.; Wang, K.; Feng, D.; Chen, Y.-P.; Verdegaal, W.; Zhou, H.-C., Incorporation of Alkylamine into Metal-Organic Frameworks through a Brønsted Acid-Base Reaction for CO2 Capture. ChemSusChem 2016, 9 (19), 2832-2840. 